\title{
DEFININDO QUALIDADE DE VIDA DE PESSOAS PORTADORAS DE PROBLEMAS DE SAÚDE MENTAL
}

Sueli Aparecida Frari Galera*

Marina Borges Teixeira**

GALERA, S.A.F. ; TEIXEIRA, M. B. Definindo qualidade de vida de pessoas portadoras de problemas de saúde mental. Rev.latino-am.enfermagem, Ribeirão Preto, v. 5, número especial, p. 69-75, maio 1997.

Este trabalho contribui para a construção do conceito de qualidade de vida a partir de incidentes críticos relatados por doentes mentais e seus acompanhantes num ambulatório de saúde mental da rede pública do Estado de São Paulo.

UNITERMOS: enfermagem psiquiátrica, qualidade de vida, técnica do incidente crítico

\section{INTRODUÇÃO}

Desde a década de sessenta a assistência psiquiátrica tem enfatizado que a doença mental pode ter um prognóstico mais otimista se o doente for tratado na comunidade onde vive e adoeceu. Desde esse período também tem aumentado o interesse pela qualidade de vida do doente mental tratado na comunidade.

Nas pesquisas sociais e de saúde, a partir da década de setenta, a qualidade de vida vem sendo definida por fatores objetivos e subjetivos que contribuem para o bem estar e para o atendimento das necessidades humanas. Estes estudos têm por premissa básica que a qualidade de vida do doente mental é um reflexo da assistência que ele recebe e por isto este tema deve ser incluído na avaliação e no planejamento da assistência (LEHEMAN, 1983; BURCHARDT et al. 1989; PINKNEY, et al, 1991; ZHAN, 1992).

Os estudos desenvolvidos por LEHEMAN (1983) e por McGILP (1991), buscam identificar quais aspectos da vida do doente são afetados pela doença mental. Para SYLVESTER \& BEAN (1989), o interesse é demonstrar que a qualidade de vida do doente mental é um fator importante que determina o tempo de permanência deste na comunidade, após uma internação psiquiátrica. Quanto melhor é a qualidade de vida na comunidade, mais tempo o doente mental consegue permanecer no seu contexto social.

Para BURCKARDT et al. (1989), um dos principais problemas das pesquisas sobre qualidade de vida diz respeito ao conceito utilizado. Estes autores afirmam que estes são, na maioria das pesquisas, unilaterais e, quase sempre, não levam em consideração a opinião de doentes ou de pessoas envolvidas com eles.

Estes conceitos são chamados de unilaterais porque foram construídos a partir da opinião de amostras de populações homogêneas (pesquisadores, populações saudáveis) sobre os aspectos que são importantes para a qualidade de vida do ser humano. Isto faz com que os pesquisadores avaliem as necessidades de populações diferentes daquelas que originaram o conceito.

Os estudos realizados por LEHEMAN (1983); SYLVESTER \& BEAN (1989); McGILP (1991) e PINKNEY, et al. (1991) são exemplos de pesquisas que utilizaram indicadores de qualidade de vida obtidas a partir deste procedimento de que nos referimos acima.

Foi com esta percepção, de que a qualidade de vida é um conceito que deve ser construído a partir da opinião de pessoas que convivem com problemas de saúde mental, que um dos autores deste estudo (GALERA, 1994) realizou uma pesquisa entrevistando 102 clientes de um ambulatório de saúde mental da rede pública do Estado de São Paulo. Pretendíamos construir um conceito segundo a opinião do próprio doente ou de pessoas que vivem próximas a ele.

\section{OBJETIVO:}

O objetivos deste trabalho é relatar os procedimentos utilizados na pesquisa e os resultados obtidos, na busca do conceito de qualidade de vida dos doentes mentais seguindo sua própria visão.

\footnotetext{
* Enfermeira, Mestre em Enfermagem Psiquiátrica

** Enfermeira, Doutor em Ciências, Professor Assitente Doutor do Departamento de Enfermagem Materno Infantil e Psiquiátrica da Escola de Enfermagem da Universidade de São Paulo
} 
REFERENCIAL METODOLÓGICO

Para orientar a pesquisa usamos a Técnica do Incidente Crítico (TIC). Esta técnica foi inicialmente desenvolvida por Flanagan em 1941 e desde então vem sendo aplicada e aprimorada em diversos campos de pesquisa, entre eles no da enfermagem.

Como exemplo de estudos que utilizaram a TIC na enfermagem citamos os trabalhos de NOGUEIRA (1988); BURCKARDT et al. (1989); CHIANCA (1992); SALVARANI (1992); NORMAN et al. (1992); COX et al. (1993) e de MINGELLA \& BENSON (1994).

A ultima revisão sobre a TIC realizada por Flanagan e seus colegas demonstrou que era possível utilizá-la em estudos sobre interações complexas como as que envolvem a qualidade de vida (FLANAGAN, 1978; 1982). Na enfermagem, BURCKARDT et al. (1989) utilizaram os trabalhos de Flanagan sobre qualidade de vida para orientar uma pesquisa sobre a qualidade de vida de pessoas portadoras de problema "crônico" de saúde física.

A técnica consiste em solicitar de entrevistados relatos verbais ou escritos, a respeito de situações vivenciadas ou presenciadas (incidentes críticos) por eles, onde a ação da pessoa contribui positiva ou negativamente para o desempenho de uma função, papel ou atividade que se está investigando. FLANAGAN (1973) preconiza cinco etapas para a utilização da TIC, estabelecer o objetivo geral da atividade, estabelecer planos e especificações, coleta de informações, análise, interpretação e registro dos resultados.

Segundo DELA COLETA (1974) incidentes críticos são situações, particularmente relevantes, observadas e relatadas pelos sujeitos entrevistados. Podem ser positivos ou negativos em função de suas consequiências para com o objetivo da atividade que se está investigando.

Para MINGELLA; BENSON (1994) incidentes críticos são vinhetas, episódios breves que resumem uma situação ou encontro de interesse.

FLANAGAN (1973) define incidente crítico como "qualquer atividade humana observável que seja suficientemente completa em si mesma de modo a permitir que se façam inferências e previsões sobre a pessoa que executa uma ação. Para ser crítico, um incidente deve conter uma situação onde o objetivo ou a intenção da ação pareça clara ao observador e onde as consequiências sejam suficientemente definidas para que deixem poucas dúvidas no que se refere aos seus efeitos".

Procedimentos adotados nesta pesquisa:

a) Definição de qualidade de vida

$\mathrm{O}$ termo qualidade de vida refere-se aos aspectos objetivos e subjetivos da vida cotidiana que contribuem para promover o bem estar, a felicidade e o atendimento das necessidades humanas (FLANAGAN, 1978; BURCKARDT et al. 1989; ZHAN, 1992).

b) Entrevista

A elaboração da entrevista teve como base as entrevistas desenvolvidas em pesquisas que utilizaram a TIC para estudar a qualidade de vida da população americana FLANAGAN (1978), e de pessoas portadoras de problemas crônicos de saúde (FLANAGAN, 1982; BURCKARDT et al., 1989).

O objetivo da entrevista foi o de extrair relatos verbais de entrevistados sobre como a doença mental interfere no seu dia a dia. O enfoque das questões foram as atividades consideradas importantes para o bem estar do doente, ou as que o deixavam feliz, contente. O objetivo e o enfoque eram apresentados ao entrevistado no início da entrevista, logo após a apresentação do entrevistador, quando este salientava a importância da opinião do entrevistado.

A técnica do incidente crítico preconiza a coleta de incidentes positivos e negativos; assim foram feitas duas questões aos entrevistados. A primeira era sobre as atividades que o doente havia deixado de fazer por causa da doença (incidentes negativos) e a segunda sobre as que ele havia deixado de fazer, mas estava conseguindo desempenhar novamente (incidentes positivos). No Anexo 1 apresentamos o roteiro da entrevista.

Para facilitar a interação com o cliente, o entrevistador utilizou os princípios do relacionamento terapêutico enfermeiro-paciente preconizados por enfermeiros psiquiátricos (PEPLAU, 1968; TRAVELBEE, 1969; ARANTES et al. 1981; STEFANELLI, 1985).

c) População

Participaram da entrevista 102 clientes, sendo 78 doentes e 24 acompanhantes de doentes, que compareceram em um ambulatório de saúde mental da rede pública do Estado de São Paulo. Os critérios para seleção dos entrevistados foram: ter mais de 15 anos, estar no ambulatório para retorno, ter condições para participar de uma entrevista e concordar em participar.

Quando o doente não parecia em condições de participar da entrevista, mas estava acompanhado, ambos participavam da entrevista. Quando estava presente somente o familiar, este era convidado a participar. Todos os acompanhantes faziam parte da família do doente e, nessa entrevista, perguntava-se sobre o dia a dia do doente.

\section{RESULTADOS E COMENTÁRIOS}

Os relatos obtidos foram sumariados e analisados segundo os cinco procedimentos preconizados por DELA COLETA (1974), que são: leitura e arrolamento dos relatos 
obtidos, identificação dos três componentes de um incidente crítico, situação, comportamento e conseqüência, agrupamento dos relatos segundo as situações, comportamentos e conseqüências semelhantes, elaboração das exigências críticas a partir dos incidentes críticos semelhantes encontrados, e análise do conteúdo que permeia todos os outros. Seguindo este procedimento, apresentamos a seguir os incidentes críticos, as exigências críticas e sua análise.

1- Incidentes Críticos

Para que os relatos obtidos nas 102 entrevistas pudessem tornar-se passíveis de análise fizemos várias leituras buscando extrair a idéia central de cada um deles. NOGUEIRA (1988) chama esta idéia central de "componente crítico específico para o objetivo da pesquisa". O componente crítico procurado nos relatos continha as atividades do dia a dia que foram ou estavam sendo afetadas pelo problema de saúde mental, ou seja as atividades consideradas importantes para o bem estar do doente.

Considerando que para ser crítico um incidente deve descrever uma situação que desencadeia uma ação e a conseqüência desta ação, procuramos descrever o conteúdo dos relatos segundo esses três componentes.

a) Categorias gerais de Situações

As categorias gerais de situações elaboradas descrevem o contexto do doente mental onde alguma atividade importante para a qualidade de vida tornou-se necessária. As situações foram agrupadas segundo a semelhança entre os contextos descritos. A ocorrência de termos semelhantes ajudou na concretização dos agrupamentos e na escolha dos títulos dados às categorias.

Uma característica comum a todas as situações descritas nos relatos é que elas apresentavam um estado de desequilíbrio na interação do doente com os contextos que compõem seu ambiente.

$\mathrm{Na}$ elaboração deste trabalho pudemos perceber também que muitas das situações relatadas se assemelham às situações de crise acidental relatadas na literatura e citadas por AGUILERA \& MESSICK (1974) e por RODRIGUES (1986). Esta semelhança chamou nossa atenção para uma questão que, em nosso entender poderá ser aprofundada futuramente, que é a relação entre os termos situações críticas e situações de crise acidental.

As situações relatadas nos incidentes críticos foram agrupadas em cinco categorias:

Trabalho: dificuldade para iniciar e completar uma tarefa do trabalho remunerado; problemas de relacionamento com pessoas do ambiente de trabalho; demissão; aposentadoria por invalidez; acidente de trabalho; dificuldade para se inserir no mercado de trabalho; pobreza decorrente da falta de trabalho.

Família: problemas de relacionamento entre o doente e membros do círculo familiar; o doente sente que perdeu seu papel junto aos seus familiares; eventos sociais propiciados pela família; separação ou divórcio; isolamento do doente em relação aos familiares; nascimento e morte de pessoa próxima.

Saúde/doença: presença de problema de saúde física em pessoas de convívio do doente; características negativas da saúde mental (é uma pessoa impressionada, é desanimado, ouve vozes, é muito nervoso, bebe muito); tratamento da doença mental (toma remédio; parou de tomar remédio, aumenta a dose do remédio); piora dos sintomas de doença física e novo diagnóstico de doença física (diabetes, câncer, problemas cardíacos).

Social: interações do doente com escola; armazém; igreja; vizinhos; festas; eventos; atividades de recreação e esporte; ausência de situações sociais; problemas legais e de segurança.

Moradia: mudança de domicílio (veio da fazenda para a cidade, mudou de cidade, mudou de bairro, ganhou casa da cohab); falta de condições financeiras para garantir moradia.

Moradia é uma categoria nova criada a partir do processo de elaboração do presente texto. Na pesquisa original (GALERA ,1994) os incidentes agrupados nesta categoria eram denominados de "Situações de Crise". Além dos problemas relacionados com a moradia, as outras situações que compunham as situações de crise eram: a menopausa e o surgimento de novos problemas de saúde (problemas ginecológicos); nascimento e morte de pessoa próxima. Estas situações foram inseridas nas categorias Saúde/doença e Família respectivamente.

b) Categorias gerais de comportamentos - Atividades críticas

As categorias gerais de comportamentos descrevem cinco atividades humanas que foram exigidas nas situações e cujo desempenho foi ou é afetado pela presença do problema de saúde mental daquele doente. Descreve também uma categoria em que o doente apresentou exacerbação dos sintomas do seu problema de saúde quando o contexto exigia uma das cinco atividades anteriores.

O desempenho destas atividades é crítico em relação à qualidade de vida e o não desempenho é indicador de que o doente está necessitando de ajuda profissional imediata.

As atividades humanas afetadas foram:

Relacionar-se com pessoas típicas do contexto: oferecer e receber ajuda de outros; brigar; pedir e dar conselhos; conversar com pessoas típicas do contexto.

Cuidar da saúde: aderir ou não ao tratamento proposto por profissional de saúde; utilizar serviço de saúde; cuidar da higiene pessoal e do ambiente.

Atividade social: fazer e receber visita; ir ao clube; 
ir jogar bola; participar de festas; aprender novas habilidades com pessoas da comunidade (aprender a dirigir automóvel; aprender a fazer comida vegetariana)

Lidar com a situação percebida como problemática: não sabe como solucionar o problema; procura solucionar o problema conversando com as pessoas envolvidas nele; adota comportamentos com a finalidade de melhorar seu humor; está sem perspectiva de como solucionar o problema; procura antecipar-se frente ao problema que começa a perceber; desiste de tentar uma solução; está tentando uma nova solução; avalia que a solução adotada foi ruim e, tenta uma nova solução.

Trabalhar: faltar ao trabalho para comparecer ao ambulatório; estar trabalhando; ir ao banco para receber salário; aposentadoria; procurar emprego; realizar trabalho doméstico e melhorias na moradia. Sintomas:_sentir falta de ar; ficar nervoso; agressivo; esquecido; ouvir vozes; sentir um negócio ruim; ver vultos; sentir uma coisa e ficar sem saída frente às exigências do contexto.

c) Categorias gerais de Conseqüências

As categorias gerais de conseqüências referemse aos resultados do desempenho das atividades exigidas nos contextos. O desempenho foi negativo quando piorou algum aspecto da vida do doente e foi positivo quando melhorou.

No estudo original (GALERA,1994) elaboramos sete categorias gerais de conseqüências, mas para a elaboração deste texto reagrupamos todas em quatro categorias gerais de conseqüências:

Piora/melhora do estado de saúde: presença de efeitos colaterais dos medicamentos; piora ou melhora de sintomas; satisfação/insatisfação com o serviço de saúde (quer mudar de médico e de hospital; gostava de conversar com aluna de enfermagem, o profissional de saúde não atendeu a solicitação do doente).

Piora/melhora do relacionamento interpessoal: melhorou seu relacionamento com colegas de trabalho; as colegas se afastaram e a doente ficou sozinha; as vizinhas mostraram que são amigas; tem alguém que se preocupa com ela; passou a ter companhia; ficou uma pessoa sozinha.

Piora/melhora do Status financeiro: começou a receber dinheiro de fonte própria; começou a receber aposentadoria; está vivendo de doações feitas por pessoas da comunidade e da família; descobriu que não tem direito a aposentadoria; foi demitido; ganha muito pouco porque poucas pessoas dão papel velho para o doente porque sabem que é doente mental; ninguém quer dar emprego ao doente; conseguiu emprego e moradia; deixou de contribuir financeiramente com a família que contava com este dinheiro. Passou ou deixou de viver em ambiente de maior ou menor conforto (casa em bairro servido por água e esgoto, casa de alvenaria, casa de favela e sem banheiro, bairro servido por transporte coletivo). Passou a ter um lugar para morar, ter comida $e$ dinheiro para os remédios.

Atividade/inatividade: está parado há 20 anos; não consegue fazer todas suas atividades como antes; está conseguindo fazer suas atividades; tem conseguido sair um pouco; não tem conseguido nem fazer as atividades de higiene pessoal; passa o dia todo na cama.

2 - Exigências Críticas

A formulação das exigências críticas é o último procedimento preconizado pela técnica do incidente crítico e envolve determinar o nível mais apropriado de especificidade-generalidade a ser utilizado na apresentação e discussão dos resultados obtidos com a técnica. Segundo FLANAGAN (1973), o nível escolhido pode ser de somente uma dúzia de comportamentos muito gerais ou de centenas de comportamentos muito específicos. Esta decisão depende dos objetivos e da natureza da atividade investigada.

DELA COLETA (1974) define exigências críticas como o conjunto de comportamentos positivos e negativos de uma dada categoria.

Neste estudo, as exigências críticas descrevem atividades de vida importantes para a interação do doente mental em cinco contextos de seu ambiente. Estas atividades foram exigidas no contexto e o desempenho do doente se refletiu em alguns aspectos de sua vida. Quando o desempenho da atividade não foi satisfatório houve uma piora em algum aspecto da vida do doente $\mathrm{e}$ quando foi satisfatório houve melhora. Na Figura 1 apresentamos as exigências críticas ou fatores que contribuem para a qualidade de vida de pessoas portadoras de algum problema de saúde mental.

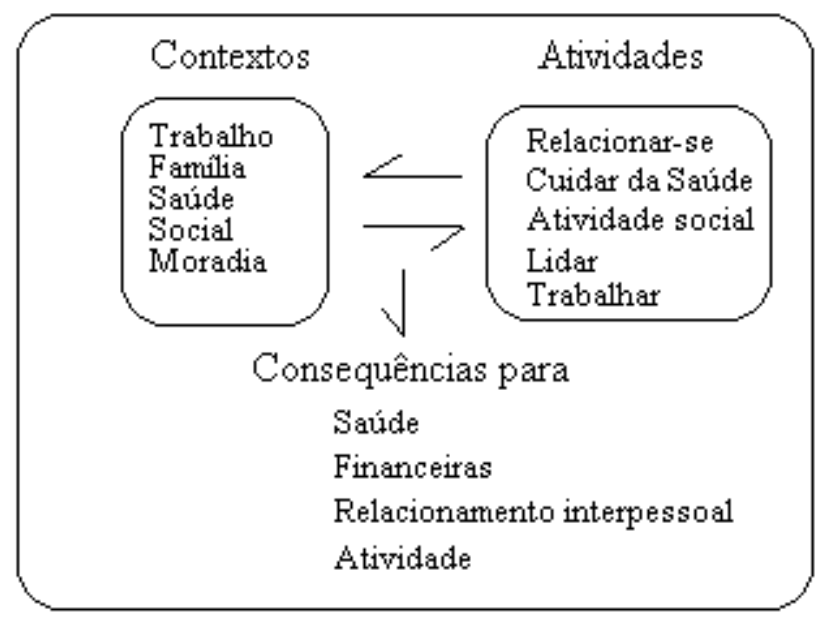

Figura 1- Fatores que contribuem para a qualidade de vida de doentes mentais tratados ambulatorialmente 
Uma das premissas quando se discute qualidade de vida do doente mental é que ela reflete a qualidade da assistência que está sendo oferecida para essas pessoas. Neste estudo encontramos algumas pessoas que estavam vivendo em condições extremas de pobreza, de isolamento e de inatividade em conseqüência de suas dificuldades para desempenhar uma ou mais atividades importantes para a qualidade de vida. Em nosso entender, essas condições extremas necessitam urgentemente de assistência.

ORLANDO (1978) alerta que quando o doente é capaz de satisfazer as suas necessidades e de efetuar as recomendações médicas sem ajuda, ele não depende da assistência do enfermeiro. Mas, quando ele não pode satisfazer as suas necessidades e não é ajudado, fica desamparado.

Concordamos com esta autora no que diz respeito ao fato de que quando não consegue solucionar seus problemas sozinhos e não recebe ajuda para isso, o doente mental fica desamparado. Contudo, gostaríamos de salientar que a assistência é de responsabilidade multidisciplinar e portanto, a responsabilidade aqui é do enfermeiro, da equipe responsável pela assistência ao doente mental e dos planejadores da assistência.

\section{CONSIDERAÇÕES FINAIS}

O conceito de qualidade de vida que se pode extrair deste trabalho dá uma dimensão da complexidade que é a vida das pessoas portadoras de algum problema de saúde mental. Esta complexidade indica que a assistência não pode ater-se somente aos aspectos da doença mental, pois os fatores que concorrem para o bem estar do doente ultrapassam estes aspectos. Esta complexidade também fala em favor de se adotar formas de assistência que possibilitem lidar com os diversos problemas que a pessoa doente enfrenta no seu dia a dia, decorrentes da doença ou de exigências do meio onde vive o doente.

Estes critérios de qualidade de vida reforçam a idéia já ressaltada por LEHEMAN (1983); SYLVESTER \& BEAN (1989) e PINCKNEY et al. (1991), de que a qualidade de vida é um elemento importante na avaliação e no planejamento da assistência, podendo contribuir para a efetivação de uma prática mais voltada para atender às reais necessidades do doente.

Consideramos importante ressaltar que o relacionamento interpessoal doente-profissional de saúde é uma atividade importante para a qualidade de vida na opinião de doentes e de seus familiares. Reforçando a idéia de que profissionais envolvidos com a assistência direta devem estar atentos e preparados para avaliar e ou modificar a qualidade de suas interações com o cliente.

Para finalizar, consideramos necessário discutir alguns aspectos metodológicos da pesquisa. Um primeiro aspecto de nossos resultados diz respeito às dificuldades para entrevistar pessoas de baixa escolaridade e portadoras de problemas de saúde mental. No entanto, o uso dos princípios do relacionamento enfermeiro-paciente combinados com a técnica do incidente crítico permitiram superar esta barreira.

NORMAN et al. (1992), pesquisadores que estudam a qualidade da assistência de enfermagem, observaram que a utilização de entrevista interativa associada à técnica do incidente crítico potencializa as oportunidades de obtenção de incidentes críticos sobre atividades complexas.

Tanto a entrevista utilizada por NORMAN et al. (1992) como os princípios do relacionamento interpessoal utilizados nesta pesquisa, são metodologias desenvolvidas no campo da enfermagem psiquiátrica. Portanto, concluímos que esta seja uma contribuição da enfermagem psiquiátrica para a adaptação da técnica do incidente crítico em estudos realizados junto a populações de baixa escolaridade, portadores de problemas de saúde e sobre temas como a qualidade de vida e qualidade da assistência recebida.

Outro aspecto metodológico que devemos salientar é que o conceito de qualidade de vida apresentado nesta pesquisa não está completo para ser utilizado na solução de problemas práticos da assistência. Até o momento estabelecemos alguns critérios. Oportunamente, é preciso determinar os aspectos subjetivos que devem compor o conceito de qualidade de vida. De acordo com FLANAGAN (1978), esta fase é fundamental para que o conceito possa ser utilizado como medida de sucesso ou fracasso com que as pessoas desempenham suas atividades.

\section{DEFINING THE QUALITY OF LIFE IN MENTALLY ILL INDIVIDUALS}

This study contributes to the construction of the quality of life concept through critical incidents reported by clients of a state mental health service.

KEY WORD: psychiatric nursing, quality of life, critical incident technique 
DEFINIENDO LA CALIDAD DE VIDA DE PERSONAS PORTADORAS DE PROBLEMAS DE SALUD MENTAL

Esta investigación contribuye para la formación del concepto de calidad de vida a partir de incidentes críticos, relatados por enfermos mentales y aconpañantes en un centro de salud mental de la red pública del estado de São Paulo.

TÉRMINOS CLAVES: enfermería psiquiátrica, calidad de vida, técnica del incidente crítico

\section{REFERÊNCIAS BIBLIOGRÁFICAS}

01. AguilerA, D. C.; MESSICK, J. M. Crisis intervention-theory and methodology. Saint Louis: Mosby, 1974.

02. ARANTES, E. C. et al. Estabelecimento de limites como medida terapêutica de relacionamento enfermeira-paciente. Rev. Esc. Enfermagem USP, v. 15, n. 2, p. 155-66, 1981.

03. BURCKARDT, C. S. et al. Quality of life of adults with chronic illness: a psychometric study. Res. Nurs. Health, v. 12, n. 6, p. 347-54, 1989.

04. CHIANCA, T. C. Uma visão sistemica do transporte do paciente cirúrgico. Ribeirão Preto, 1992. Dissertação (Mestrado)-Escola de Enfermagem de Ribeirão Preto, Universidade de São Paulo.

05. COX, K. et al. Exploring consumer views of care provided by Macmillan nurse using the critical incident technique. J. Adv. Nurs., v. 18, n. 3, p. 408-15, 1993.

06. DELA COLETA, J. A. A técnica dos incidentes críticos - aplicações e resultados. Arq. Bras. Psicol. Apl., v. 26, n. 2, p. 35-58, 1974.

07. FlanAGAN, J. C. A técnica do incidente crítico. Arq. Bras. Psicol. Apl., v. 25, n. 2, p. 99-141, 1973.

08. FLANAGAN, J. C. A research approach to improving our quality of life. Am Psychol., v. 33, n. 2, p. 138-47, 1978.

09. FLANAGAN, J. C. Measurement of quality of life: current state of the art. Arch. Phys. Med. Rehabil., v. 63, n. 1, p. 56-9, 1982.

10. GALERA, S. A. F. Contribuição ao estudo da qualidade de vida de doentes mentais tratados ambulatorialmente. São Paulo, 1994. Dissertação (Mestrado)-Escola de Enfermagem, Universidade de São Paulo.

11. LEHEMAN, A. F. The well-being of chronic mental patient. Arch. Gen. Psychiatry, v. 40, p. 36973, Apr. 1983.

12. McGILP, D. A. A quality of life study of discharged long-term psychiatric patients. J. Adv. Nurs., v. 16, n. 10, p. 1206-15, 1991.
13.MINGHELLA, E.; BENSON, A. Developing reflective practice in mental health nursing through critical incident analysis. J. Adv. Nurs., v. 21, p. 205-13, 1994.

14. NOGUEIRA, M. S. Incidentes críticos na passagem de plantão. Ribeirão Preto, 1988. Dissertação (Mestrado)-Escola de Enfermagem de Ribeirão Preto, Universidade de São Paulo.

15. NORMAN, I. J. et al. Developing Flanagan's critical incident techinique to elicit indicators of high and low nursing care from patients an their nurses. J. Adv. Nurs., v. 17, n. 5, p. 590-600, 1992.

16. ORLANDO, I. J. O relacionamento dinâmico enfermeiro/paciente. São Paulo: EPU, 1978.

17. PEPLAU, H. E. Princípios básicos para la orientacion del paciente. Washington: Organizacion Panamericana de la Salud, 1968 (Publ. científica, 167).

18. PINKNEY, A. A.; GERBER, G. J. ; LAFAVE, H. G. Quality of life after psychiatric rehabilitation: the client's perspective. Acta Psychiatr. Scand, v. 83, n. 2, p. 86-91, 1991.

19. RODRIGUES, A. R. F. Enfermagem de saúde mental para mulheres em crise acidental. Ribeirão Preto, 1986. Tese (Doutorado)-Escola de Enfermagem, Universidade de São Paulo.

20. SALVARANI, M. C. O paciente cirúrgico e suas expectativas de comunicação com a enfermeira. Ribeirão Preto, 1992. Dissertação (Mestrado)-Escola de Enfermagem de Ribeirão Preto, Universidade de São Paulo.

21. STEFANELLI, M. C. Ensino de técnicas de comunicação terapêutica enfermeirapaciente. São Paulo, 1985. Tese (Doutorado)Escola de Enfermagem, Universidade de São Paulo.

22. SYlVESTER, C. T.; BEAN, G. J. Prediting community tenure after psychaiatric hopitalization. Community Ment. Health J., v. 25, n. 2, p. 105-20, 1989.

23. TRAVELBEE, J. Intervencion em enfermeria psiquiátrica. Cali, Carvayal, 1969.

24. ZHAN, L. Quality of life: conceptual and measurement issues. J. Adv. Nurs., v. 17, n. 7, p. 795-800, 1992. 


\section{ANEXO 1}

Roteiro da entrevista

Apresentação do entrevistador: Meu nome é S...., sou enfermeira e aluna de pós-graduação da Escola de Enfermagem da USP. Estou realizando uma pesquisa junto aos clientes deste ambulatório. Esta pesquisa faz parte de meus estudos. Muitas pessoas têm afirmado que a doença mental interfere na vida dos doentes. Estou interessada em conhecer como é o dia a dia das pessoas que têm algum problema de saúde mental. Acredito que o (a) Sr (a) está apto a fornecer este tipo de informação. Por isso gostaria de lhe fazer algumas perguntas. Devo salientar que por se tratar de uma pesquisa as informações serão publicadas, mas os nomes dos entrevistados não serão identificados.

Questões negativas: Pense nesta semana que passou. Tente se lembrar de alguma coisa que você (o doente) queria muito fazer e seu problema de saúde mental impediu você de fazer. Alguma coisa que iria deixar você (o doente) satisfeito. O quê você queria fazer e não pode fazer? Como foi? ou Tente se lembrar de alguma coisa que aconteceu com você (com o doente) que o deixou (o doente) insatisfeito.

Questões positivas: Agora tente se lembrar da alguma coisa que normalmente você (o doente) tem dificuldade de fazer e esta semana você (o doente) fez. O quê você (o doente) fez? Conte-me como foi. Ou, tente se lembrar de alguma coisa que aconteceu com você (o doente) que o deixou satisfeito. 